\title{
Discussion: Implementing UK reservoir safety - thoughts on future needs
}

Andy K. Hughes BSc, PhD, DMS, CEng, FICE, FCIWEM, MIMgt Atkins Ltd, Epsom, Surrey, UK (andy.hughes@damsandreservoirs.co.uk)
Peter J. Mason BSc, MPhil, PhD, FICE, CEng

Director, Damsolve Ltd, High Wycombe, UK (peter.mason@damsolve.com)
I read Peter Mason's paper (Mason, 2020) with interest but I felt I had to comment to avoid confusion and also to warn against legislative change to no benefit.

My comments are:

- The All Reservoirs (AR) Forums were started by the late Michael Kennard to provide what it 'says on the can' - a private forum so that AR panel engineers could share concerns, problems and experiences on all aspects of the role. I remember on my first attendance topics included a case on internal erosion and how to deal with a client who wouldn't pay!

- I don't understand the statement 'Wales...... have produced their own legislation' - this is not true - England and Wales have the same legislation - it's just applied in a different way!

- The reason for an 'observer' in the AR Forum is that some time ago a senior member of the Environment Agency suggested that the forum was a 'closed shop' where a cartel could be set up - wrongly in my opinion - as a group of professionals bound by the ICE Code of Practice. A decision was made to include an observer that started as Paul Taylor from the ICE and Secretary to the Reservoirs Committee. Later it changed to one of the employees of the regulators. I personally do not think this is beneficial or necessary, particularly because those who attend have to pay for the hire of the room at the ICE, the IT facilities and lunch and the observer has refused in the past!!

- The 'sample' used for the questionnaire is very small and includes a number of engineers who have had very little experience of the role. The 'membership' of the forum has now been expanded to include non-impounding reservoirs (NIR) and service reservoirs (SR) panel engineers. I warn against making decisions on such a small sample particularly as the questions were not seen before the forum and there was no discussion on the questions.

- I would agree the scatter is certainly due to the "wide variety of personal experience'.

- There is currently no UK formal guidance on spillways best practice. After Toddbrook I wrote a two page briefing note on the failures at Toddbrook, Ulley, Butterley and Naden, as an informative note to heighten awareness. We used to receive these bulletins regularly from the
Environment Agency at Exeter but have not received any for many years and on this occasion someone decided not to issue my contribution.

Looking at the questions I worry about the responses and the interpretations:

- Limiting supervising engineers (SEs) to 50 reservoirs does not recognise that Pennine dams are very different to say ornamental lakes or farmers' irrigation ponds - the latter having very limited pipework, spillways which are often a pipe to a stream and so on. They take very less time and when clustered in a geographical area or when there are several in a series it is possible to examine five to seven reservoirs on a summer's day.

- A reference pack is always available for an inspection - if not offered an engineer only has to ask!

- Why can't an engineer provide SE and inspecting engineer (IE) services on the same reservoir? - We are professionals. There are pros and cons, but if professional and an engineer wants to do this type of work and it is economically acceptable, why not? The engineer develops a far greater understanding of the behaviour of the reservoir over years, the owner, the maintenance regime and so on. This knowledge often makes Section 10 inspection a less expensive exercise in the year that it is due. In addition, the owner often likes to deal with just one engineer - and there are 'no surprises' when Section 10 inspection is carried out. The owner should decide, not legislation.

- The examination of spillways should also be carried out each year by a SE or IE and often twice a year and the report format should always cover the aspects quoted if the standard format devised by myself, back in 1992, is followed.

- Failure mode analysis (FMA) by 'a small selected team' is suggested - the simplicity of the system and the individual responsibility of a panel engineer was always seen as a benefit of the UK legislative system. Inspection by 'committee' was examined and rejected in the past. Surely by continuous continuing professional development (CPD) an individual engineer should be able to carry out an FMA - and should have been done at Toddbrook.

- All Reservoirs panel engineers, in my experience, always meet the owner during and/or after the inspection and by 
way of a draft report and discussions to ensure the reason for recommendations and timescales are fully understood. Why is it necessary to increase the bureaucracy to get a certificate which has to be 'jointly' signed? In the case of Toddbrook I understand the recommendations and timescales were explained and the 'owner' understood what was being said. A jointly signed certificate would not have helped.

- SE's can call for an inspection at any time. Again, this decision has to be made based on professional judgement and experience. Maintenance is often done intermittently at times when it becomes necessary - so I can see problems if judgement is not exercised. Again, it's all to do with the relationship and trust experienced between owner and $\mathrm{SE}$ - it can't be legislated for.

- I cannot see that changing the wording of Certificates under 10(6) to be 'fit for purpose' is possible - no engineer will be able to do this - to cover a period of 10 years, or get it past his insurers!

Thank goodness the questions, that are grouped as 'tendency to reject', were rejected!

- When one looks at the inspection process now in England and Wales, the IE has to give a written explanation to the owner and regulator if he has not submitted his report within 6 months ( 9 months in Scotland). To me this is an indication that an IE should be able to submit a final report within 6 months. I am still seeing reports submitted up to a year after the inspection date in England and I remember back in the 1980s, when I was at North West Water (now United Utilities), one engineer took over 3 years to submit reports - not as an opportunity to 'catch up' or 'remedy deficiencies' - he merely was slow!

- I totally support a move against tendering of statutory inspections. I see this with SE appointments where some are bid low just to try to ensure the firm concerned then gets the inspection under Section 10 and the follow-on work - in my opinion very unprofessional. I do not accept that 'low bidding' should favour a 'minimal inspection' - the inspection has to be complete and extensive otherwise the individual is not acting professionally.

- The inspection process surely does include using the previous Section 10 reports over a number of decades to form the basis of an inspection report of a dam - its history, the works carried out and so on - so why is it not acceptable to pre-write part of a report on the historical features and aspects expected to be found? Research before an inspection allows one to ask more pertinent questions, saving time and allowing more focus.

- 'A number's game' - I have already warned against numbers. The analysis given assumes all dams are the same - clearly they are not - some are very simple with no instrumentation, some more difficult and some very complex. Whether Dr Mason accepts it or not, if the previous inspection is properly reported on it does make the process of inspection and report more easy and less time consuming. I agree that the cost of insurance is an issue and is likely to become more of an issue and this then influences and relates to the price paid for an inspection and the 'value' that owners are prepared to pay for a panel engineer. Some engineers are known not to carry their own insurance.

- Satellite data were presented in my report on Toddbrook (Hughes, 2020) but this was dismissed by the author. I believe the evidence presented showed the progressive nature of the failure at Toddbrook over many decades and that satellite data will have a greater presence in monitoring regimes in the future.

- I believe a 'target compliance' for data is setting a dangerous precedence. Surely again judgement and pragmatism can be applied without changes to legislation. Surely an SE knows how to react if an owner just doesn't bother to take readings compared to one who misses a day here or there?

- I completely agree with the comments on scour discharges - there does not seem to be a will to try to resolve the problem - but it must be solved. I threw out a challenge to the Environment Agency more than six years ago and it still hasn't been solved. There is also another issue with some dams associated with the hydraulic capacity of the receiving stream. What is clear is that if we can get through the initial problem then regular operation will overcome many of the issues associated with sediment release, scour of river channels, stream capacity and low oxygen contents. In some instances, the ruling of the Hampstead Heath Society v the City of London (Hughes, 2016) can help.

- I agree that we are basing our legislation on the basis of consequence of failure - sense must prevail at some stage!

- Again, I agree the Scottish system - high, medium and low - is better than any other legislative format in the UK.

- In my experience owners in Scotland seem to wait to receive comprehensive reports, similar to those produced in Wales and England.

I personally believe the present IE system covers all of the concerns of the author. Surely an engineer can decide whether he needs to seek additional assistance to carrying out a comprehensive review and report. He can commission this in a number of ways.

However regrettably, recently I carried out inspections where a 24 inch syphon was not even mentioned in the report and 
where the reason for wave overtopping was totally missed, and of course at Toddbrook a risk assessment declared the auxiliary spillway as adequate.

Problems are occurring and will continue to occur.

Will the proposed changes actually catch all problems - I think not - there are far larger issues to deal with!!!

\section{REFERENCES}

Hughes AK (2016) Hampstead heath - a ruling from the honourable Mrs justice land DBE. Dams and Reservoirs 26(3): 133-143, https://doi.org/10.1680/jdare.16.00037.

Hughes AK (2020) Report on the Nature and Root Cause of the Toddbrook Reservoir Auxiliary Spillway. Canal and River Trust, Milton Keynes, UK.

Mason PJ (2020) Implementing UK reservoir safety - thoughts on future needs. Dams and Reservoirs 30(3): 78-84, https://doi.org/10. 1680/jdare.20.00014

\section{Response to contribution by Dr. A. K. Hughes}

Firstly, I must thank Dr. Hughes for responding to my paper and I was pleased to see that so many of his views align with my own. Indeed, the other personal responses I have had to my paper have all been very positive. It also gives me the opportunity to expand on some aspects of my paper for further clarity and to comment on some of the other matters raised by Dr. Hughes and on some matters of detail.

The primary legislation for reservoir safety in Wales is indeed essentially The Reservoir Act (1975). The legislation to which I was referring was that undertaken to adapt it to use in Wales, such as 'Welsh Statutory Instrument 2016 No. 78 (W. 35), Flood Risk Management Wales, The Reservoirs Act 1975 (Exemptions, Appeals and Inspections) (Wales) Regulations 2016' (NAfW, 2016). Of course, the NAW also legislated to adopt $10000 \mathrm{~m}^{3}$ as a lower threshold for reservoirs to come under the Act in Wales rather than the $25000 \mathrm{~m}^{3}$ still adopted in England.

At the time of the last panel forum there were 30 registered All-Reservoir panel engineers (ARPEs) in the UK plus, I understand, four on the service reservoirs (SR) panel and one on the non-impounding reservoirs (NIR) panel. In the event there were 28 panel attendees at the Forum of which 26 were ARPEs and two from other panels. Regrettably, Dr. Hughes did not attend due to other commitments. Each question received 25 or 26 votes which simple maths suggests must represent the views of somewhere between 80 and $87 \%$ of the UK's ARPE and not the 'small sample' suggested by Dr. Hughes. Their experience inevitably varies, and as I note in the paper, this is likely reflected in the scoring. However, all have gone through a rigorous appointment process based on that experience and on their knowledge and professionalism. I do not think it appropriate to suggest that all their views are not equally valid.

The questions asked were not, incidentally, my own. At the time of the Forum, I was assisting Professor Balmforth with his investigation into the Toddbrook incident. During this we undertook a series of interviews with the owner, operators, other engineers and members of the public. Inevitably speculation arose in such discussions about what changes to current procedures may usefully offset similar incidents in future, not necessarily at Toddbrook, but more generally. The questions assembled for the Forum and listed in Table 1 of my paper came from those discussions.

Dr. Hughes makes various comments related to Toddbook and so perhaps I can deal with those together. I believe certain aspects of the briefing note he prepared were indeed incorporated in the eventual advisory notice on the incident produced by the Environment Agency. In one place Dr. Hughes suggests that a failure mode analysis (FMA) should have been done at Toddbrook. In fact, as he acknowledges in another point, a preliminary risk assessment was done, and the results incorporated in the April 2019 inspection report. However, the risk assessment did not, as Dr. Hughes suggests, 'declare the spillway as adequate'. The results are quoted in Table 4 of the inspection report and concluded that 'hydro-dynamic damage to the secondary overflow channel' represents both a credible and significant risk. It is why, of the seven mandatory measures stipulated in that report, 'In the Interests of Safety', the first two related to the secondary spillway. For a definitive explanation to the causes of the failure at Toddbrook I would, of course, recommend my own paper, recently published in Dams \& Reservoirs, 'Toddbrook: the independent government review, a forensic approach to causality' (Mason, 2020).

Contrary to the statement by Dr. Hughes, the satellite information at Toddbrook was not dismissed. It was indeed taken seriously at the time. However, the data were un-verified and apparently produced as a marketing exercise by a specialist company, using generally available 'InSAR' data. The data did not, as implied, go back decades but rather just a year. Lastly it was noted that spillway slabs sitting on fill are of course designed to accommodate some settlement and to articulate with separate slabs linked by dowel bars to keep them aligned and to avoid 'steps'. This would seem to have worked well at Toddbrook. Prior to the eventual internal collapse of an individual chute slab all appear to have stayed structurally intact on the auxiliary spillway chute. In short, even if the data were valid, it was difficult to demonstrate an immediate causal link to the chute collapse.

Matters have, however, moved on from that initial assessment and it has not proved possible to verify or replicate the 20-30 $\mathrm{mm}$ isolated drops in level previous suggested. A later 
independent review by qualified Earth Observation scientists at HR Wallingford was unable to replicate these results. Careful post-processing of the same InSAR data, coupled with checks using other satellite geometry datasets was carried out. They also noted that $27 \mathrm{~mm}$ was a very specific and common processing error using InSAR data as it corresponds to exactly half the radar's wavelength. Further in-depth analysis would be necessary before any firm conclusions can be drawn on movement at this specific site. However, I would agree with Dr. Hughes that the use of satellites for monitoring on our projects has a great future and is also something I have been advocating for many years. I would also advocate localised three-dimensional mapping and time comparisons using drone technology.

The issue of compliance is an interesting one. Currently, the supervising engineer is required to report on the undertaker's compliance in their annual statement to the regulator. If, say, weekly recordings of given data have been specified by the inspecting engineer and over the course of a year, some are missing then, that is a legal non-compliance. Furthermore, the regulator is then also obliged to include it in regular Reservoir Safety reports. There are no 'degrees' of this and while some might argue pragmatically that a dozen or so gaps in the record might be acceptable over the course of a year, others might put the number at two or three. Strictly speaking, compliance means compliance and for a conscientious supervising engineer that means $100 \%$. I know from personal experience that this is already causing distress to some in the industry where they are being legally required to report non-compliances that, in their engineering judgement, are unlikely to affect reservoir safety. My proposal is that the matter can be easily resolved by the wording the inspecting engineers use in their reports. It simply means that they make that pragmatic judgement based on their experience and on the reservoir in question and so relieve the supervising engineers from potential personal and professional conflicts.

Dr. Hughes is of course correct in saying that some reservoir visits can be shorter than others and groups of reservoirs in close proximity can facilitate this. I suspect the ARPEs marking this were reflecting on more typical times involved for things like travel, walking around the main dam including mitres and downstream hillsides and inspecting the condition of spillways and other structures. Discussions with the undertaker and ensuring that the prescribed form of record is up to date can also be time consuming, as can inspecting and reviewing any monitoring data for indications of significant change. Where companies employ full-time supervising engineers, I have found that 50 reservoirs per engineer is a not uncommon limit but would agree that I have seen higher. However as noted in the paper, two APRE's wrote on their mark sheets that they felt the upper limit should be 30 .
Whether the same engineer should provide both supervising and inspecting duties at the same reservoir was not an issue at Toddbrook. The roles were clearly separated. However, it did come up several times in the course of general discussions during the course of the Toddbrook investigations. Indeed, some to whom we spoke thought that the current Act already prevented such a duplication of roles and said they saw it as a potential conflict of interest. I can recall one case many years ago where the joint role was abused with the engineer in question calling for inspections which he then carried out, effectively creating work for himself. Eventually he was removed from the panel. I suspect those marking this question must have asked themselves, why have a situation where such a conflict is possible when a small rule change can simply eliminate it? I can see the advantages of sharing both duties in terms of cost and knowledge of the reservoir. The alternative argument is that a fresh pair of eyes can be beneficial. In fact, I know a number of owners who deliberately change inspecting engineers every 10 years simply to get the benefit of alternative views and opinions.

With regard to report writing, of course, it does no harm to start drafting some basic background information about a reservoir prior to an inspection. Indeed, it is an excellent familiarisation process. However, I was especially surprised at the suggestion of a reference pack always being available. 'Something' is always available but certainly not always beforehand. I have turned up at reservoirs when even the prescribed form of record has been lost. In four cases the reservoirs involved were major category A reservoirs. Where prior information is received, in my experience it is never complete. The existence of other information and data generally emerges from discussions during the course of the inspection and which then has to be requested and reviewed. It is a process that can take weeks and months. At Toddbrook the key as-built drawing of the secondary spillway only emerged six weeks after the inspection had taken place.

Lastly, we come to errors in reports. I assume that the omissions mentioned at the end of Dr. Hughes note relate to reports that he was given. Regrettably my experience has been similar. In recent times I have seen a report which described a concrete parapet wall along the upstream face of a dam and even detailed its dimensions. In fact, the crest of the dam in question featured galvanised steel handrailing. The same report listed levels for a series of spillway openings which varied by as much as $8 \mathrm{~m}$ whereas in reality they were all effectively the same. In another report that crossed my path recently, flood levels appeared to have been copied from the previous inspection report 10 years before, except that the maximum reservoir level including a wave allowance, had wrongly been copied as a still water level implying a much larger flood. A further wave allowance had then been 
erroneously added to that which would have over-topped the parapet crest wall had the level of the wall in question not also been incorrectly quoted as a metre higher than it should have been. Unfortunately, the incorrect flood data have been copied into the emergency preparedness plan for the reservoir. I can only but agree with Dr. Hughes that problems continue. Whether some better rigour can be brought by some of the changes mentioned in my paper is not something I can claim. However I do hope that a continued searching for improvement in the processes involved may assist with that.

\section{REFERENCES}

Mason PJ (2020) Toddbrook: the independent government review - a forensic approach to causality. Dams and Reservoirs 30(4): 153-164. NAfW (National Assembly for Wales) (2016) Welsh Statutory Instrument 2016 No. 78 (W. 35), Flood Risk Management Wales, The Reservoirs Act 1975 (Exemptions, Appeals and Inspections) (Wales) Regulations 2016. HMSO, London, UK. 